\title{
European UV DataBase (EUVDB) as a repository and quality analyser for solar spectral UV irradiance monitored in Sodankylä
}

\author{
Anu Heikkilä ${ }^{1}$, Jussi Kaurola ${ }^{2}$, Kaisa Lakkala ${ }^{1,3}$, Juha Matti Karhu ${ }^{4}$, Esko Kyrö ${ }^{4}$, Tapani Koskela ${ }^{5}$, Ola Engelsen $^{6}$, \\ Harry Slaper $^{7}$, and Gunther Seckmeyer ${ }^{8}$ \\ ${ }^{1}$ Finnish Meteorological Institute, R\&D/Climate Research, Helsinki, Finland \\ ${ }^{2}$ Finnish Meteorological Institute, Weather and Safety, Helsinki, Finland \\ ${ }^{3}$ Finnish Meteorological Institute, R\&D/Arctic Research Center, Rovaniemi, Finland \\ ${ }^{4}$ Finnish Meteorological Institute, R\&D/Arctic Research Center, Sodankylä, Finland \\ ${ }^{5}$ Independent researcher, Helsinki, Finland \\ ${ }^{6}$ Norwegian Institute for Air Research, Troms $\varnothing$, Norway \\ ${ }^{7}$ National Institute for Public Health and the Environment, Utrecht, the Netherlands \\ ${ }^{8}$ Leibnitz Universität Hannover, Institute of Meteorology and Climatology, Hanover, Germany
}

Correspondence to: Anu Heikkilä (anu.heikkila@fmi.fi)

Received: 7 December 2015 - Published in Geosci. Instrum. Method. Data Syst. Discuss.: 18 January 2016

Revised: 17 June 2016 - Accepted: 27 June 2016 - Published: 1 August 2016

\begin{abstract}
Databases gathering atmospheric data have great potential not only as data storages but also in serving as platforms for coherent quality assurance (QA). We report on the flagging system and QA tools designed for and implemented in the European UV DataBase (EUVDB; http://uv.fmi.fi/ $\mathrm{uvdb} /$ ) for measured data on solar spectral UV irradiance. We confine the study on the data measured by Brewer \#037 MkII spectroradiometer in Sodankylä $\left(67.37^{\circ} \mathrm{N}, 26.63^{\circ} \mathrm{E}\right)$ in 1990-2014. The quality indicators associated with the UV irradiance spectra uploaded into the database are retrieved from the database and subjected to a statistical analysis. The study demonstrates the performance of the QA tools of the EUVDB. In addition, it yields an overall view of the availability and quality of the solar UV spectra recorded in Sodankylä over a quarter of a century. Over $90 \%$ of the four main quality indicators are flagged as GREEN, indicating the highest achievable quality. For the BLACK flags, denoting data not meeting the pre-defined requirements, the percentages for all the indicators remain below $0.12 \%$.
\end{abstract}

\section{Introduction}

Monitoring the state of the Earth's atmosphere and the living conditions at the Earth's surface requires measurements of high quality. This is a rule that applies to all atmospheric pa- rameters and variables, including solar UV irradiance. General guidelines for quality control (QC) and quality assurance (QA) in solar UV irradiance measurements have been carefully formulated (Webb et al., 1998, 2003; Seckmeyer et al., 2001, 2005, 2010a, b). Following the guidelines facilitates recognition of all potential sources of errors, reduction of the effect of all those sources on the overall uncertainty of the measurements, and production of data of as high quality as possible. However, to verify the efficiency of the recommended QC/QA measures taken, tools to analyse the quality of data are needed.

Databases established for experimental atmospheric data have great potential, in providing not only consistent formats, centralized collection, and efficient dissemination for a large number of data, but also coherent procedures for QA. The European UV DataBase (EUVDB; http://uv.fmi. $\mathrm{fi} / \mathrm{uvdb} /$ ) was established as a joint effort of 25 participants from 15 European countries within the framework of two projects: SUVDAMA (Scientific UV Data Management) in 1996-1999 and EDUCE (European Database for UV Climatology and Evaluation) in 1999-2002, funded by the 4th and 5th framework programmes of the EU, respectively. The projects included development of comprehensive QA tools, to be applied to all the solar spectral UV irradiance data submitted to the database. 
Currently, the EUVDB has 111 registered users representing 61 different organizations. The number of registered stations is 49 , of which 47 have submitted spectral and/or broadband data on solar UV irradiance over the years of the existence of the database. Two sites locate outside Europe: Lauder in New Zealand and Princess Elisabeth Antarctic base in Antarctica. The number of stations having reported spectral UV data is 37 , of which 35 stations with long-term spectral UV measurements and two sites having hosted a measurement campaign. In the Northern Hemisphere, the geographical coverage of the database extends from $28.49^{\circ} \mathrm{N}$ (Izaña, Tenerife, Spain) to $69.66^{\circ} \mathrm{N}$ (Troms $\varnothing$, Norway) in latitude and from $27.22^{\circ} \mathrm{W}$ (Angra do Heroísmo, Azores, Portugal) to $26.63^{\circ} \mathrm{E}$ (Sodankylä, Finland) in longitude. The altitudes of the sites vary from $2 \mathrm{~m}$ a.s.l. (Leba, Poland) to $3106 \mathrm{~m}$ a.s.l. (Sonnblick, Austria). Substantial records of solar spectral UV irradiance data extending over 10-23 years are available from 12 sites. Five of these sites provide data sets covering over 20 years of measurements. These sites are the very same ones that continue reporting their spectral UV data regularly to the database.

The role of the centralized QA tools should not be seen as replacements for the existing on-site quality-check procedures. Within the EUVDB, the data providers are therefore encouraged to continue conducting their own QC actions and following the generally accepted guidelines therein. The QA tools of the database are targeted to supplement the on-site procedures, to verify that they have been applied successfully to the data, and give uniformity to the data sets originating from a large number of geographically scattered stations. In addition, the tools are meant to enable selection of data according to the requirements of the user.

Over the operational years, the tools once developed have provided valuable information on the quality of the data, readily available to both the users and the providers of the data (Seckmeyer, 2002, 2004). Instruments measuring spectral UV irradiance are delicate and subject to several environmental factors influencing their performance and the reliability of their measurements. In addition, the maintenance of their calibration is challenging (e.g. Mäkelä et al., 2016). Instrumental errors may lead to erroneous interpretations on the amount of UV radiation reaching the surface of the Earth (e.g. McKenzie et al., 2015) and should be therefore minimized in every possible way. Efforts to increase costeffectiveness and automation in ground-based measurements of solar UV irradiance further emphasize the importance of the centralized QA tools.

We report on the tools implemented in the European UV DataBase for the QA of the solar spectral UV irradiance data uploaded by the data provider to the database. Data measured by Brewer \#037 MkII single monochromator spectroradiometer over the years 1990-2014 in Sodankylä, Finland, are used to demonstrate the performance of the tools. The selected data set provides a subject for a case study. The quality indicators are examined for their values (i.e. colours), and the frequency distribution of the colours, denoting different categories of quality, is derived for each indicator. In addition, selected case spectra, representing different categories of quality, are studied in detail. For the first time, a comprehensive analysis on the quality of UV irradiance spectra measured by Brewer \#037 in Sodankylä is presented.

\section{Materials and methods}

\subsection{Brewer spectrophotometer in solar spectral UV irradiance measurements}

The Brewer spectrophotometer is primarily used to measure atmospheric total column ozone and solar spectral UV irradiance (Bais et al., 1996; Brewer, 1973). In addition, its measurements may be used to derive atmospheric sulfur dioxide $\mathrm{SO}_{2}$ (Cappellani and Bielli, 1995), nitrogen dioxide $\mathrm{NO}_{2}$ (e.g. Cede et al., 2006; Diémoz et al., 2014), and aerosol optical depth (Gröbner et al., 2001; Kazadzis et al., 2005; Marenco et al., 2002). The instrument consists of foreoptics to collect photons of solar UV radiation, a monochromator to separate the irradiance (photons) into spectral components at specific wavelengths, a photomultiplier tube as a radiation detector, and a sun tracker to follow the position of the Sun in the sky. Brewer \#037 MkII spectrophotometer in Sodankylä employs a single monochromator. Rejection of stray light is more challenging to the single than to double monochromators, especially at wavelengths below $305 \mathrm{~nm}$ (Bais et al., 1996). The wavelength range of the instrument is $290-325 \mathrm{~nm}$.

The Brewer spectrophotometer is designed to operate fully automatically following a schedule predefined by the operator. The schedule contains command strings, each denoting a measurement or an instrumental test performed by the spectrometer. Measurement of solar UV irradiance spectrum is scheduled to take place at least every $30 \mathrm{~min}$, typically every $20 \mathrm{~min}$. Measurements for total column ozone are done between the UV scans, either as direct sun, zenith sky or focused sun measurements, depending on the air mass (Karppinen et al., 2016). The schedules have slightly changed over time but the main principles have stayed as described above. Currently, the schedule is defined for each day separately to optimize the number of measurements. Between the sky measurements, the spectrometer makes tests, which are used as QC tools to monitor, for instance, the performance of the motors aligning the optics and the photomultiplier tube detecting the photons.

\subsection{QA tools and flagging in EUVDB}

The European UV DataBase (EUVDB) contains a specific subpage listing all the sites and instruments registered into the database. The page provides site- and instrument-specific information for the users of the data. In addition, it gives tabular and graphical summaries on the monthly number of solar 
Table 1. General descriptions of the quality flags.

\begin{tabular}{ll}
\hline Flag & Description \\
\hline GREEN & Meets predefined* standard quality \\
YELLOW & Some (minor) deviation \\
RED & $\begin{array}{l}\text { Indicates errors potentially problematic } \\
\text { for certain applications }\end{array}$ \\
GREY & Flagging not possible \\
BLACK & Does not meet quality requirements \\
* Criteria as recommended for type S-1 spectral instruments by \\
Seckmeyer et al. (2001).
\end{tabular}

UV spectra submitted to the database. The summaries may be used as indicators on the availability of data. The database user may find the summaries very helpful since they allow quick browsing of the availability of data, prior to actual data retrieval. They can also be used in an inverse manner to infer the number of missing data, i.e. gaps in the time series.

The QA performed on the UV irradiance data submitted to and stored in the EUVDB is based on a package named CheckUVSpec containing two algorithms independent of each other: AtmosphericSignature and ShicRIVM (http://www.rivm.nl/shicrivm; Slaper et al., 1995, Williams et al., 2003). The package produces indicators on the quality of the principal elements of UV irradiance spectra: the wavelength scale, the irradiance scale, and the shape of the spectrum. In addition, it yields diagnostic information on atmospheric conditions and variability of conditions during the scan. The package is an integrated part of the database, run automatically in every event of data submission. Inclusion of several different indicators allows checking of the data for different aspects of quality and potential atmospheric conditions.

The quality indicators are denoted flags, associated with a selection of colours (summarized in Table 1). GREEN flag is reserved for the spectra meeting the highest-quality criteria. YELLOW is used for those not fully complying with the highest criteria, but satisfying the secondary criteria. RED flag is raised for a spectrum not meeting even the secondary criteria, but still exceeding the rejection criteria. For spectra meeting the rejection criteria, a BLACK flag is given. In the case that no definite conclusion on the quality of a doubtful spectrum can be drawn, the spectrum is marked with a GREY flag. Flags are given for a number of different properties of the spectrum. In addition, a master flag, describing the overall quality, is given to the spectrum.

\subsubsection{AtmosphericSignature}

The AtmosphericSignature QA tool is based on examination of differences between the measured and modelled solar UV irradiance spectra. For model calculations of spectral UV irradiance, the tool employs the FastRT programme (http: //zardoz.nilu.no/ olaeng/fastrt/fastrt.html). Spectral UV irra- diance is simulated for a range of well-defined atmospheric scenarios. Descriptions of the scenarios denoted as MIN, MAX, AERO, CLEA, and CLOU are given in Table 2. The irradiance of the measured spectrum is compared to that of the simulated scenarios on two narrow instrument-specific wavelength bands: one on the lower end and one in the upper end of the measured spectral region. For the single monochromator Brewer \#037 with a spectral range of 290 $325 \mathrm{~nm}$, only the lower band (at $315.0-316.0 \mathrm{~nm}$ ) is used. The metrics used for the flagging are listed in Table 3. Examination of the metrics results in placing the spectrum into one of the following categories:

- Too high radiation level: The irradiance exceeds even the scenario of multiple scattering including snowcovered surface and clouds trapping and enhancing radiation on the ground.

- Enhanced radiation: The irradiance exceeds the level normally encountered under clear-sky conditions. GREEN flag indicates highly reflective ground. In the case of a YELLOW flag, special cloud conditions must prevail in addition to the highly reflective surface.

- Clear sky: The irradiance indicates cloudless-sky conditions.

- Moving clouds: The irradiance spectrum contains features indicating clouds appearing or disappearing during the scan. Two different cases are dealt with: CLNCU (cloud at lower band - no cloud at upper band), and NCL-CU (no cloud at lower band - cloud at upper band)

- Clouds: The irradiance indicates cloudy conditions.

- Too low radiation level: The irradiance is even lower than that under extremely thick rainy clouds.

- Too high solar zenith angle: The solar zenith angle during the scan exceeds $84^{\circ}$. The model calculations do not yield results accurate enough. The flags are GREY.

The threshold values for the metrics were subject to exhaustive discussion and set within the EDUCE project. In the QA tool running in the database, they are implemented as constant values and can be changed neither by the submitter nor by the user of the data.

\subsubsection{ShicRIVM}

ShicRIVM (www.rivm.nl/shic) is a software package developed for QA, correction, and homogenization of spectral UV irradiance data. It uses the Fraunhofer lines in the solar UV spectrum for the wavelength alignment of the measured ground-based spectrum. The structures have been derived from solar measurements at Kitt Peak National Observatory in Arizona, US (Kurucz et al., 1984), resulting in a 
Table 2. Atmospheric scenarios defined in and used by the QA tool AtmosphericSignature.

\begin{tabular}{|c|c|}
\hline Scenario & Description \\
\hline MIN & $\begin{array}{l}\text { The lowest naturally observable radiation levels, assumed to prevail under a homogenous, extremely thick } \\
\text { water cloud (altostratus; Shettle, 1990) with thickness of } 4 \mathrm{~km} \text { and liquid water column of } 4000 \mathrm{~g} \mathrm{~m}^{-2} \text {, } \\
\text { equivalent to a cloud optical depth of } 650 \text { at a wavelength of } 360 \mathrm{~nm} \text {. No surface reflection. }\end{array}$ \\
\hline MAX & $\begin{array}{l}\text { Broken clouds scenario, the downwelling radiation assumed to be transmitted through a clear atmosphere } \\
\text { and getting trapped between a snow-covered ground and an extremely thick homogenous altostratus cloud. } \\
\text { The MAX scenario is assumed to yield the highest radiation levels obtainable naturally. }\end{array}$ \\
\hline MAX_0 & $\begin{array}{l}\text { The MAX scenario with all diffuse downward radiation transmitted through the clear atmosphere absorbed } \\
\text { and scattered by the thick homogeneous cloud. }\end{array}$ \\
\hline AERO & Cloudless but very turbid aerosol-loaded atmosphere with a visibility of $5 \mathrm{~km}$. No surface reflection. \\
\hline CLEA & Clear atmosphere with no aerosols or clouds present. No surface reflection. \\
\hline CLOU & $\begin{array}{l}\text { Cloudy atmosphere similar to MAX but with variable cloud density. Model simulations are run iteratively } \\
\text { to find the cloud liquid water column yielding the best match between measurements and modelling. }\end{array}$ \\
\hline
\end{tabular}

Table 3. Categories of atmospheric conditions estimated by the QA tool AtmosphericSignature on the basis of comparison of the measured and simulated solar UV irradiance spectrum. Metrics used for the estimation and determination of the associated colour for the Atm_signature flag. Symbol $m$ denotes the measured irradiance. Symbols MIN, MAX, AERO, and CLEA denote the irradiance simulated for the corresponding scenarios. Subscripts 1 and 2 refer to the wavelength bands used for comparison (measured vs. modelled) in the lower and upper part of the UV spectral region, respectively.

\begin{tabular}{|c|c|c|}
\hline Metric, $f$ & Atmospheric conditions & Atm_signature colour \\
\hline$\frac{m_{2}}{\mathrm{MAX}_{2}}$ & Too high radiation level & $\begin{array}{l}\text { BLACK if } f>1.15 \\
\text { RED if } 0.85<f<=1.15\end{array}$ \\
\hline$\frac{m_{2}-\mathrm{CLEA}_{2}}{\mathrm{MAX}_{2}-\mathrm{CLEA}_{2}}$ & Enhanced radiation & $\begin{array}{l}\text { YELLOW if } m_{2}>\text { MAX }_{2-0} \\
\text { GREEN otherwise }\end{array}$ \\
\hline $\begin{array}{l}\text { Atmospheric visibility }(5-340 \mathrm{~km}) \\
\mathrm{CLEA}_{2}, \mathrm{AERO}_{2}\end{array}$ & Clear sky & GREEN \\
\hline $\begin{array}{l}M_{1} / M_{2}-\mathrm{CLEA}_{1} / \mathrm{CLEA}_{2} \\
M_{1} / M_{2}-\mathrm{MIN}_{1} / \mathrm{MIN}_{2}\end{array}$ & $\begin{array}{l}\text { Moving clouds } \\
\text { CL-NCU, } f<-0.15 \\
\text { NCL-CU, } f>0.15\end{array}$ & GREEN \\
\hline $\begin{array}{l}\text { Cloud liquid water column } \\
\left(\mathrm{g} \mathrm{m}^{-2}\right)\end{array}$ & Clouds & GREEN \\
\hline$\frac{m_{2}}{\mathrm{MIN}_{2}}$ & $\begin{array}{l}\text { Too low radiation level } \\
\text { Too high }\left(>84^{\circ}\right) \text { solar zenith angle }\end{array}$ & $\begin{array}{l}\text { RED } \\
\text { GREY }\end{array}$ \\
\hline
\end{tabular}

high-resolution extraterrestrial (ET) spectrum with a highly accurate wavelength scale. The ET spectrum is multiplied with the simulated atmospheric transmission and convolved with the instrumental slit function of the spectroradiometer. The atmospheric transmission is calculated using a modified version of the simple model of McKenzie (1991). The algorithm is not sensitive to the applied model for the atmospheric transmission because it uses the local spectral structures $(0.5-2 \mathrm{~nm}$ off the nominal) dominated by the Fraunhofer structures.
The software is able to detect shifts in the wavelength scale, determine the lowest detectable irradiance level, and identify anomalies like spikes in the shape of the spectrum. It has been extensively tested with a variety of spectrometers in various conditions during large intercomparison campaigns of spectroradiometers (e.g. CAMSSUM 1995 (Gardiner and Kirsch, 1997), SUSPEN 1997 (Bais et al., 2001), NOGIC 1996 (Koskela et al., 1997), NOGIC 2000, MAUVE/CUVRA, QASUME 1999) and several smaller campaigns. The accuracy of the wavelength check has been shown to be less than $0.02 \mathrm{~nm}$ for spectrometers with full 
width at half maximum less than $1 \mathrm{~nm}$ (Slaper and Koskela, 1997). The method used to determine the lowest detectable irradiance level has been applied to several different instruments with readings at a wide range of solar zenith angles and compared to the method developed by Bernhard et al. (1998), applying the ratio of subsequent spectral measurements from a single instrument. The results were comparable.

In the EUVDB, only the diagnostic (QA) part of the package is implemented as an inherent quality analyser for the incoming data. Consequently, no corrections on data are performed in the database. For the diagnostics, the tool uses specific indicators (flags) named Shift1, Shift2, Start_irr, and Spike_shape. Descriptions of the indicators are given in the following.

\section{Shift1: flag for detecting wavelength shifts in the wavelength range $300-325 \mathrm{~nm}$}

The wavelength shift is calculated by using the ratio of irradiance at each wavelength to the irradiance at the neighbouring two wavelengths, effectively quantifying the fine structure of the spectrum. The ratios computed from the (ground-based) measured and modelled spectrum are compared. As the fine structures of the modelled and the measured spectra should be similar, a difference between the two ratios reveals a shift in the wavelength scale. The algorithm is described in detail in Slaper et al. (1995).

The shift in nanometres is given in the detailed flag description of the spectrum. The colour of the flag is determined on the basis of the following criteria: $0 \mathrm{~nm}<$ GREEN $<0.1 \mathrm{~nm}<$ YELLOW $<0.2 \mathrm{~nm}<$ RED $<0.4 \mathrm{~nm}<$ BLACK. In the case that the algorithm fails to yield at least five reliable shift determinations, or if the general criteria indicate BLACK but the median irradiance in the vicinity of $310 \mathrm{~nm}$ remains below $5 \times 10^{-4} \mathrm{~W} \mathrm{~m}^{-2} \mathrm{~nm}^{-1}$, the flag is marked as GREY.

\section{Shift2: flag for detecting wavelength shifts in the wavelength range of $325-400 \mathrm{~nm}$}

The shift in nanometres is given in the detailed flag description of the spectrum. The colour of the flag is determined on the basis of the following criteria: $0 \mathrm{~nm}<$ GREEN $<0.1 \mathrm{~nm}$ $<$ YELLOW $<0.2 \mathrm{~nm}<$ RED $<0.4 \mathrm{~nm}<$ BLACK. In the case that the wavelength range of the spectrum does not extend over $325 \mathrm{~nm}$, value 9.999 is returned and the indicator is flagged as GREY. If a wavelength shift is definitely detectable at less than five wavelengths, or if the flag is BLACK but the median irradiance around $310 \mathrm{~nm}$ is lower than $5 \times 10^{-4} \mathrm{~W} \mathrm{~m}^{-2} \mathrm{~nm}^{-1}$, the flag is returned as GREY. In the case that the wavelength scale of the instrument does not extend to the wavelength range on which Shift2 operates, the indicator Shift2 is set as GREY to all spectra and is not taken into account in the determination of the master flag.

\section{Start_irr: flag for the lowest reliable irradiance reading}

In order to determine where the reported spectral irradiance starts to exceed the noise level of the instrument, the algorithm takes the ratio of the measured spectral irradiance at the lowest reported wavelength to the spectral irradiance at the next higher wavelength. Five such ratios at subsequent wavelengths are compared with simulated modelled ratios. If all these ratios compare within $25 \%$ with the modelled ratios, the lowest of these readings is taken as the irradiance level at which the spectrum becomes reliable. If the criterion is not met, the same procedure is repeated starting with the irradiance ratios at the next measured wavelengths. When the criterion is met, the reading at the lowest wavelength is considered the start irradiance level. In the case that one of the irradiance readings at lower wavelengths is higher, the start irradiance level is increased to the highest irradiance level obtained in the noisy spectral region. This higher value is taken as an indication that the noise level is higher than the level obtained following the ratio method.

Two numeric values are output in the detailed flag description of the spectrum: irradiance at the first reliable reading and the highest irradiance below the first reliable reading. The colour of the flag is determined on the basis of the following criteria set for the higher of the two irradiance values: GREEN $<5 \times 10^{-1} \mathrm{~W} \mathrm{~m}^{-2} \mathrm{~nm}^{-1}<$ YELLOW $<1.5 \times 10^{-3} \mathrm{~W} \mathrm{~m}^{-2} \mathrm{~nm}^{-1}<\mathrm{RED}<5 \times 10^{-3} \mathrm{~W} \mathrm{~m}^{-2} \mathrm{~nm}^{-1}$ $<$ BLACK. If the median irradiance level around $310 \mathrm{~nm}$ is lower than $5 \times 10^{-1} \mathrm{~W} \mathrm{~m}^{-2} \mathrm{~nm}^{-1}$, the flag is set as GREY.

\section{Spike_shape: flag for spikes and anomalies in the local shape of the spectrum}

If the ratio of the irradiance reading and the median of 10 readings around the measured wavelength is more than double to that found in the spectrum obtained by model calculations, the feature is interpreted as a spike, and a BLACK flag is returned. A RED flag results from a ratio of two irradiance readings at consecutive wavelengths in the spectrum deviating more than $50 \%$ from the corresponding modelled ratio. In the case that the deviation exceeds $25 \%$, and yet remains below $50 \%$, a YELLOW flag is given. The local shape is examined through the differences between the ratios of two irradiance readings at consecutive wavelengths in the measured and the modelled spectrum. The following criteria are used for the flagging of the local shape: GREEN $<10 \%<$ YELLOW $<15 \%<$ RED $<20 \%<$ BLACK. The worse of the two flags determines the overall colour of the flag Spike_shape.

Two indicators of the atmospheric conditions are included in addition to the flags mentioned above. The first one is aimed at investigating the atmospheric transmission, and the second is used to identify variability of conditions during the scan. The descriptions of these are given below. 
Table 4. ShicRIVM categories of atmospheric transmission normalized to unity for cloudless sky, and the associated colours for the Transmission_2 flag.

\begin{tabular}{lll}
\hline $\begin{array}{l}\text { Transmission } \\
\text { flag }\end{array}$ & $\begin{array}{l}\text { Transmission_2 } \\
\text { colour }\end{array}$ & Description \\
\hline$>2.0$ & BLACK & Extremely high transmission \\
$>1.5$ & RED & Very very high transmission \\
$>1.25$ & YELLOW & Very high transmission \\
$>0.75$ & GREEN & Low or no clouds \\
$>0.25$ & GREEN & Clouds \\
$>0.10$ & GREEN & Thick clouds \\
$>0.05$ & YELLOW & Very thick clouds \\
$>0.01$ & RED & Very very thick clouds \\
$<0.01$ & BLACK & Extremely low transmission \\
\hline
\end{tabular}

Transmission_2: indicator of the average transmission in the wavelength range of $315-325 \mathrm{~nm}$

The transmission is calculated by accounting for the EarthSun distance, and normalized to unity for cloudless sky. Table 4 summarizes the descriptions of the defined categories of transmission and the associated colours of the Transmission_2 flag.

\section{Scan_variability_2: indicator of the variability in the atmospheric transmission during the scan for the wavelength range $325-400 \mathrm{~nm}$}

Diagnostic identifier for large variations occurring during a scan. As the wavelength scale of Brewer \#037 ends at $325 \mathrm{~nm}$, this flag is marked NOT_DETERMINED for all Brewer \#037 UV irradiance spectra in the EUVDB.

\subsubsection{Master flag}

The indicators determining the colour of the master flag are Shift1, Shift2, Start_irr, Spike_shape, and Atm_signature. In the case that the wavelength scale of the instrument does not extend to the wavelength range on which Shift2 operates, the indicator Shift 2 is not taken into account in the determination of the master flag. The worst value of any of these indicators determine the colour of the master flag. If one of them is YELLOW and all others are green, the master flag is YELLOW. If one of them is RED and all others are GREEN or YELLOW, the master flag is RED. If one of them is BLACK and all others are GREEN, YELLOW, or RED, the master flag is BLACK. In the case that any of these indicators is GREY, the master flag is also set as GREY, independent of the other colours received by the other indicators.

\subsection{Retrieval of flags for Sodankylä Brewer \#037}

The quality of the solar UV irradiance spectra measured by the Brewer \#037 in the Arctic Research Center of the Finnish Meteorological Institute in Sodankylä $\left(67.37^{\circ} \mathrm{N}\right.$, $26.63^{\circ} \mathrm{E} ; 170 \mathrm{~m}$ a.s.1.) and submitted to the EUVDB database for the years 1990-2014 was examined by retrieving the flag information concerning each individual spectrum. The retrieval was done by using the PL/SQL tools provided by the database through its www-based interface (Fig. 1). The interface allows the user to retrieve information on master flags of all colours or to restrict the query on a subset of master flag colours. In addition, the user may retrieve information on spectra measured in all atmospheric conditions or concentrate on specific prevailing conditions. In this study, the retrieval was done by choosing all colours of the master flag and all kinds of atmospheric scenarios.

The files containing the flags obtained by retrieval were examined by using an ad hoc script written in Perl (Practical Extraction and Report Language). The total numbers of each flag colour for the indicators Shift1, Shift2, Start_irr, Spike_shape, Transmission_2 and Atm_signature, and for the overall indicator master, were computed in total and for each year separately. The monthly distribution of the different colours was also examined for potential seasonal dependence.

In addition to the calculations, the data were viewed through the tabular and graphical summaries provided by the database itself. Figure 2 presents the monthly number of UV irradiance spectra measured by Brewer \#037 over the years 1990-2014 as displayed on the screen by the www-based interface to the database.

\section{Results}

The statistical calculations performed with the Perl script on the flag data retrieved for the Sodankylä Brewer \#037 from the EUVDB were examined in detail and summarized. The measurements of solar UV irradiance using Brewer \#037 were started on 5 April 1990. The total number of spectra submitted into the EUVDB until the end of 2014 is 133444. For the year 1990, the database includes 2519 UV irradiance spectra. Over the years 1991-2014, the total annual number of spectra varies between 4656 and 6724, the average annual number of spectra being 5455 .

The annual number of scans varies for several reasons. Five main factors affecting the annual number of collected scans can be distinguished, described briefly in the following:

1. Annual maintenance and calibrations for total column ozone measurements have caused breaks of varying durations in the solar UV measurements. Calibration performed in Finland (in Sodankylä or in Jokioinen) has caused a break of 5-7 days into the time series of the solar UV scans. The gap caused by an intercomparison campaign abroad has been longer, typically from 2 weeks to 1 month. The lengths and timings of these gaps vary from year to year, resulting in variability in 
Spectrum type and quality flag

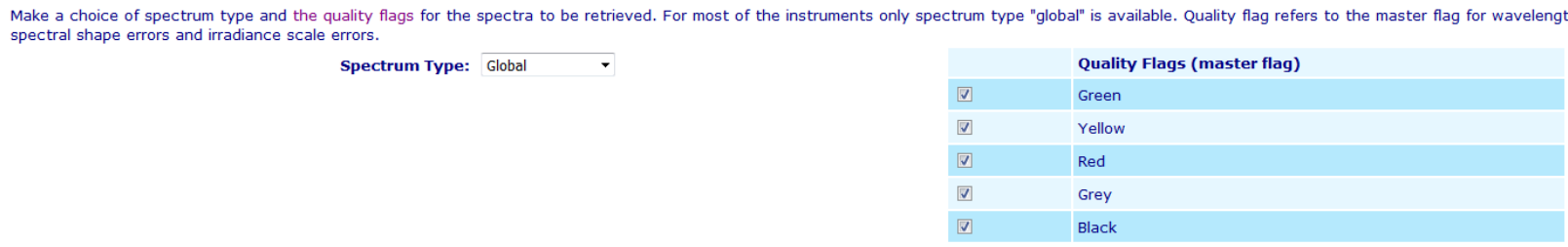

Prevailing atmospheric condition

\begin{tabular}{|c|c|c|c|}
\hline & CheckUVSpec: see infobox for details & & ShicRIVM: see infobox for details \\
\hline [ & Too high radiation level (RED or BLACK) & $\nabla$ & Extremely high $(>2.0$, BLACK) \\
\hline [ & Enhanced radiation(YELLOW or GREEN) & 四 & Very very high $(>1.5$, RED) \\
\hline 目 & Clear sky (GREEN) & 四 & Very high ( $>1.25$, YELLOW) \\
\hline 四 & Moving clouds (GREEN) & v & Low or no clouds ( $>0.75$, GREEN) \\
\hline [ & Clouds (GREEN) & v & Clouds ( $>0.25$, GREEN) \\
\hline च & Too low radiation level (RED) & v & Thick clouds (>0.1, GREEN) \\
\hline \multirow[t]{3}{*}{$\nabla$} & Too high solar zenith angle ( $>84$ degrees, GREY)) & 四 & Very thick clouds ( $>0.05$. YELLOW) \\
\hline & & v & Very very thick clouds ( $>0.01, \mathrm{RED})$ \\
\hline & & $\nabla$ & Extremely low $(<0.01$, BLACK $)$ \\
\hline
\end{tabular}

Figure 1. Screenshot on the www-based interface for making query into the EUVDB. The query may be restricted to a desired subset of flag colours.

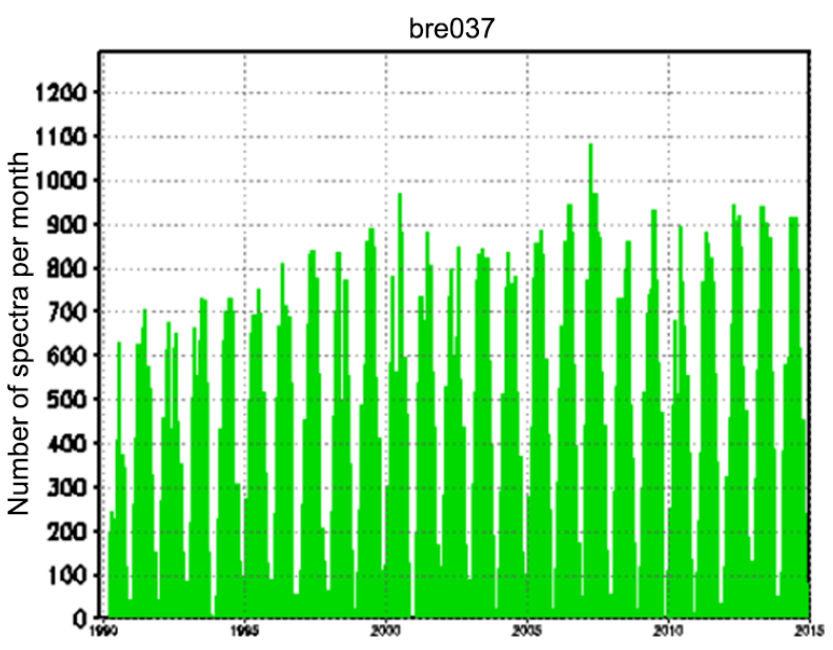

Figure 2. Graphical summary on the spectral UV irradiance data measured by Brewer \#037 in Sodankylä in 1990-2014: monthly number of spectra as a screenshot of the on-the-screen display by the www-based interface to the database.

the number of solar UV scans collected annually at the home site of Brewer \#037.

2. Brewer \#037 has been calibrated for UV irradiance by performing lamp measurements in the optical laboratory of the Arctic Research Center of the Finnish Meteorological Institute in Sodankylä. Typically, the frequency of these measurements has been 6-8 weeks. However, there are year-to-year differences in the frequency due to, for instance, the availability of personnel capable of performing the measurements.
3. The operating software of Brewer \#037 seizes up from time to time. This may have resulted in a loss of several UV scans. The software has been under long-term development by the supplier IOS Inc. over the years, resulting in a number of updated versions of the software with enhanced operational reliability. Some of the versions have been more prone to seize up than the others. Hence, the number of jams due to the software varies from year to year.

4. The frequency the Brewer \#037 performs solar UV scans is regulated by pre-defined schedules. The schedules have been updated over the operational years. Improved sampling of the diurnal cycle of the solar UV irradiance has been one of the objectives when redefining the schedules. The number of scheduled daily UV scans has therefore increased over the years.

5. The on-site QC/QA procedures reject part of the measured spectra as erroneous. All data submitted to EUVDB is subject to final (Level 2) QA including wavelength correction employing the programme ShicRIVM. All the scanned spectra are also visually inspected and compared against ancillary broadband and modelled UV data (Lakkala et al., 2008), and clearly erroneous spectra are rejected. Typically 5 to 10 spectra are rejected annually at that stage. This QA procedure has been followed since 2005. The minimum number of annually rejected spectra per year since 2005 is one (in 2010 and in 2014). The corresponding maximum number of spectra is 16 (in 2007). Over the years 19902004 , the number of spectra rejected at the final stage of QA has been larger. 
All of the above-mentioned factors introduce variability to the annual number of collected scans of solar UV irradiance. The first three factors may be estimated to be more significant than the last two.

Table 5 summarizes the statistics on the quality indicators as flag colours given to the Sodankylä Brewer \#037 UV irradiance spectra in the EUVDB. In terms of the indicator Start_irr, over $99 \%$ of the spectra were flagged as GREEN. For the indicator Transmission_2, the percentage of the GREEN flags is over $95 \%$. For the indicators Shift1 and Spike_shape, the relative frequencies of the GREEN flags are over $90 \%$. The percentage of the GREEN flags for the indicator Atm_signature is only $\sim 67 \%$, appearing relatively low in comparison. The result is mainly explained by the fact that the algorithm of the tool AtmosphericSignature sets the Atm_signature indicator to GREY whenever the solar zenith angle has been too high $\left(>84^{\circ}\right)$ for accurate enough model calculations. This is a frequent occurrence for Sodankylä, located within the polar circle, where the sun can be low for several consecutive scans after sunrise and before sunset.

According to the results listed in Table 5, the master flag given to the spectra is GREEN in only about $61 \%$ of the cases. The relatively large fraction of the GREY flags received by the indicator Atm_signature $(23 \%)$ is the major reason for the low number of GREEN master flags. Part of the GREY flags may be traced to the cases with high solar zenith angle that Sodankylä as a high-latitude site has plenty of. Cases with high solar zenith angle are challenging to both the spectrometer measuring solar UV irradiance and to the model simulating solar UV irradiance to be used as a reference by the QA tool. From the perspective of QA, more emphasis should be therefore put onto the other indicators. However, the Atm_signature flag should yield useful information on the prevailing atmospheric conditions. For Sodankylä Brewer \#037, the Atm_signature could be therefore used to extract cases representing particular measurement conditions of interest.

Figure 3 presents the monthly distribution of the colours received by the master flag. As may be expected, the share of the GREEN flags is smaller in the winter than in the summer. In December, all master flags are GREY. The share of the GREEN flags is largest in June (77\%). The share of the BLACK flags is largest in July $(0.23 \%)$.

To demonstrate the performance of the QA tools and the flagging system of the EUVDB in more detail, five cases were selected to be investigated more thoroughly. The case spectra and the related flag information are summarized in Table 6. The corresponding spectra are also shown in Figs. 45. In the following, each of the cases is examined separately.

\subsection{Case 1: all flags GREEN (Fig. 4)}

This is a typical summertime UV irradiance spectrum near the local noon, with cloudless or almost cloudless sky. All quality indicators are GREEN, except Shift2, which is GREY

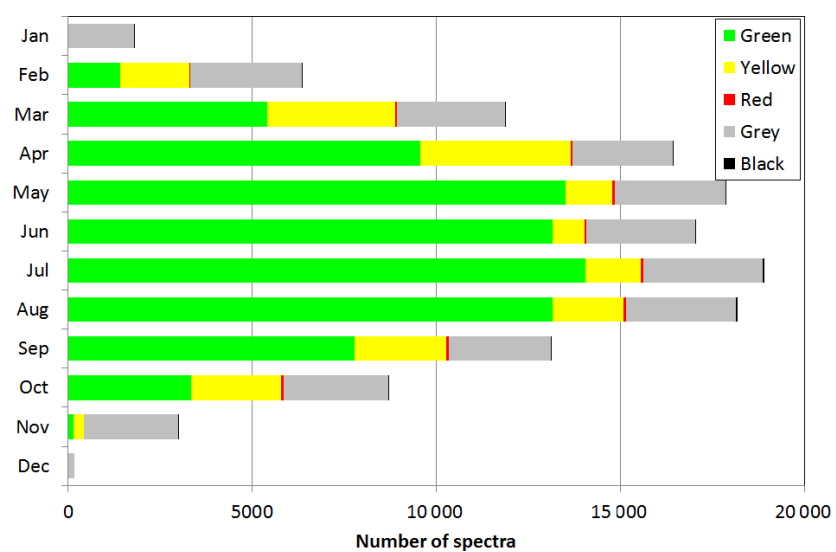

Figure 3. Monthly distribution of the colours received by the master flag.

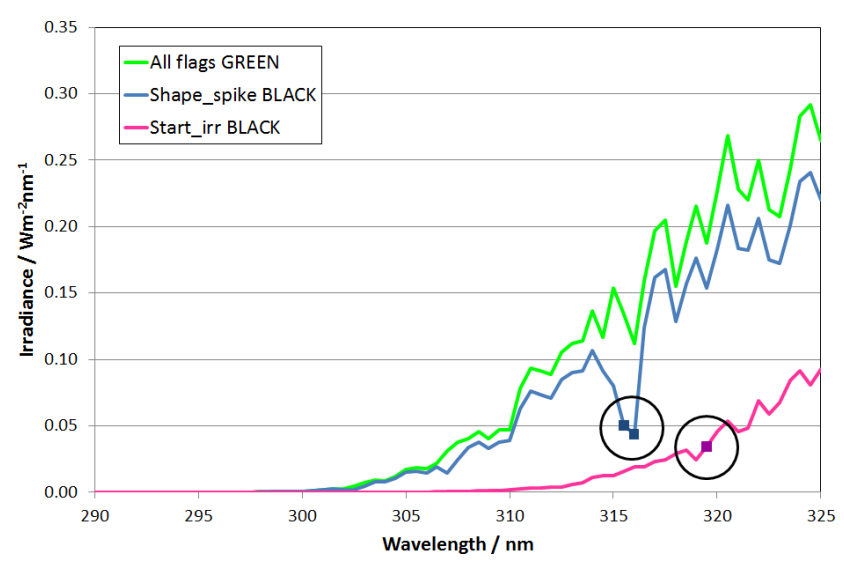

Figure 4. Exemplar spectra of three different cases. (1) Case of a GREEN flag given to all individual indicators. Spectrum measured by Brewer \#037 in Sodankylä on 21 June 2003, at 10:00:22 UTC. (2) Case of a BLACK flag given to the shape of the spectrum (indicator named Shape_spike). A dip in the spectrum at $316 \mathrm{~nm}$ is clearly distinguishable. Spectrum measured by Brewer \#037 in Sodankylä on 8 July 2003, at 07:26:59 UTC. (3) Case of a BLACK flag given to the lowest reliable irradiance reading (indicator named Start_irr). Spectrum measured by Brewer \#037 in Sodankylä on 26 March, at 11:54:24 UTC.

for all Sodankylä spectra, and Scan_variability_2, which has a value of NOT_DETERMINED, since the wavelength range does not exceed $325 \mathrm{~nm}$. No anomalies occur in the shape of the spectrum.

\subsection{Case 2: Spike_shape flag BLACK (Fig. 4)}

This is a typical example of a spectrum containing a spike. In this spectrum, the spike occurs as a sharp dip at wavelengths 315.5 and $316.0 \mathrm{~nm}$. The reason for the spike is likely of instrumental origin. 
Table 5. Absolute and relative frequencies of different flag colours given by the QA tools of the European UV DataBase (EUVDB) for the UV irradiance spectra measured by the Sodankylä Brewer \#037 over the years 1990-2014.

\begin{tabular}{lllllll}
\hline Flag colour & Shift1 & Start_irr & Spike_shape & Transmission_2 & Atm_signature & Master \\
\hline GREEN & 121419 & 133117 & 120924 & 127158 & 89484 & 81511 \\
YELLOW & 0 & 133 & 10761 & 5619 & 14740 & 20252 \\
RED & 0 & 71 & 1510 & 491 & 64 & 540 \\
GREY & 12025 & 51 & 116 & 174 & 29156 & 30986 \\
BLACK & 0 & 72 & 133 & 2 & 0 & 155 \\
GREEN & $90.99 \%$ & $99.75 \%$ & $90.62 \%$ & $95.29 \%$ & $67.06 \%$ & $61.08 \%$ \\
YELLOW & $0.00 \%$ & $0.10 \%$ & $8.06 \%$ & $4.21 \%$ & $11.05 \%$ & $15.18 \%$ \\
RED & $0.00 \%$ & $0.05 \%$ & $1.13 \%$ & $0.37 \%$ & $0.05 \%$ & $0.40 \%$ \\
GREY & $9.01 \%$ & $0.04 \%$ & $0.09 \%$ & $0.13 \%$ & $21.85 \%$ & $23.22 \%$ \\
BLACK & $0.00 \%$ & $0.06 \%$ & $0.10 \%$ & $0.00 \%$ & $0.00 \%$ & $0.12 \%$ \\
\hline
\end{tabular}

Total number of spectra: 133444

Table 6. Cases of UV irradiance spectra retrieved from the EUVDB as representatives for different flag colours of the various quality indicators. Case 1 used as a reference with all flags GREEN; cases 2-5 representing spectra for which a particular quality indicator flagged as BLACK or GREY (in boldface).

\begin{tabular}{lllllllll}
\hline No. & Date & UTC & Shift1 & Start_irr & Spike_shape & Transmission_2 & Atm_signature & Master \\
\hline 1 & 21 June 2003 & 10.01 & GREEN & GREEN & GREEN & GREEN & GREEN & GREEN \\
2 & 8 July 2003 & 7.45 & GREY & GREEN & BLACK & GREEN & GREEN & BLACK \\
3 & 26 March 2003 & 11.91 & GREY & BLACK & YELLOW & GREEN & GREEN & BLACK \\
4 & 21 June 2003 & 20.44 & GREY & GREEN & GREEN & GREEN & GREY & GREY \\
5 & 9 October 1992 & 14.14 & GREEN & GREEN & GREEN & BLACK & GREY & BLACK \\
\hline
\end{tabular}

\subsection{Case 3: Start_irr flag BLACK (Fig. 4)}

The spectrum is an example of a case where the algorithm detects the first irradiance reading emerging from the noise as far as at $319.5 \mathrm{~nm}$ at the level of $0.034 \mathrm{Wm}^{-2} \mathrm{~nm}^{-1}$. The reading exceeds the limit set for the BLACK flag $(5 \times$ $10^{-3} \mathrm{Wm}^{-2} \mathrm{~nm}^{-1}$ ), and hence the flag is set BLACK.

\subsection{Case 4: Shift1 flag GREY (Fig. 5)}

No BLACK flags were given to the Shift1 indicator, and hence we chose to examine one of the GREY flag cases here. This is a case where irradiance at $310 \mathrm{~nm}$ has remained below $5 \times 10^{-1} \mathrm{Wm}^{-2} \mathrm{~nm}^{-1}$ due to low signal late in the evening and in the presence of clouds. The algorithm cannot make any conclusions concerning possible shifts in the wavelength scale, and the GREY flag is returned.

\subsection{Case 5: Transmission_2 flag BLACK (Fig. 5)}

Only two spectra were flagged in the studied data set as BLACK for the quality indicator Transmission_2. In the case shown here, the ShicRIVM tool had associated the spectrum with an atmosphere of extremely high $(\sim 2.3)$ transmission. The scan has been started at solar zenith angle of $\sim 85.5^{\circ}$, and hence the AtmosphericSignature tool has not been able to make any supporting conclusions on the atmospheric con-

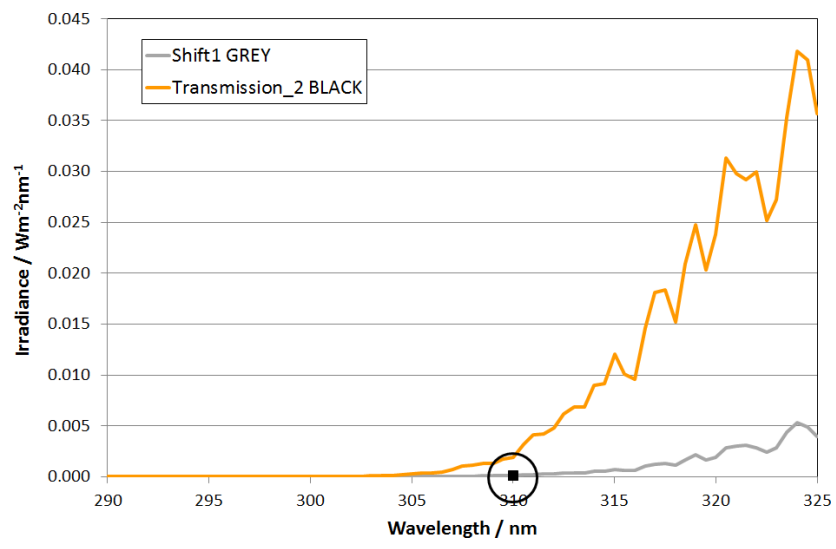

Figure 5. Exemplar spectra of two different cases. (1) Case of a GREY flag given to the potential shifts in the wavelength scale (indicator named Shift1). Spectrum measured by Brewer \#037 in Sodankylä on 21 June 2003, at 20:26:33 UTC. (2) Case of a BLACK flag given to the atmospheric transmission (indicator named Transmission_2). Spectrum measured by Brewer \#037 in Sodankylä on 9 October 1992, at 14:08:10 UTC

ditions. For the preceding scans, enhanced irradiance has been noted by the AtmosphericSignature tool. 


\section{Discussion}

Analysis on the mere statistics of the flag information is obviously an efficient way to get an overall view on different aspects of the quality. However, a detailed examination of selected cases as described above is apt to give even more profound insight into the data studied and the special characteristics therein. Specifically, an understanding on the metrics and categorization used by the different quality indicators helps the data provider and the user in analysing and using the data in a meaningful way. Clearly, the indicators provide an added value to the data set.

The quality of solar spectral UV irradiance measurements has been addressed and exhaustively discussed ever since the launch of the first long-term monitoring programmes in the late 1980s. While there is no actual standard up-to-date definition of the requirements set to high-quality UV irradiance data, a common understanding on the requirements is shared by the scientific community and documented in the reports prepared by international advisory groups (Webb et al., 1998, 2003; Seckmeyer et al., 2001, 2005, 2010a, b).

In general, the required quality depends on the scientific question. These could be site-specific issues or questions in a wider context, analysing geographical differences and their causes, for example, as has been done by Seckmeyer et al. (2008a, b). For these two studies, spectra with green flags have been used only. Alternatively, the analysis may focus on a specific question like estimating probability functions (Voskrebenzev et al., 2015), where more spectra with nongreen flags may be included.

Currently, the QA tools of the EUVDB are mainly used to complement the on-site $\mathrm{QC}$ routines. In addition, they could be used to remotely monitor the performance of the instrument at an unmanned station. If the spectra were automatically uploaded into the EUVDB, the QA flags of the database could alert on a problem with the wavelength setting (Shift1, Shift2), or snow/dirt covering the entrance optics of the instrument and blocking the incoming radiation (Start_irr, Spike_shape, Too low irradiance). They could also be used to separate scans made under changing cloud conditions (Spike_shape, Moving clouds), in the case that the data are used for validation of near-real-time satellite data or model calculations. As one solar UV scan takes up to $3 \mathrm{~min}$, the cloud conditions may change during the scan, affecting the reliability of the comparison.

It should be noted that re-evaluation of the spectral UV irradiance data sets subjected to even the most rigorous QC/QA procedures may reveal previously undetected features in the data (see, e.g. Garane et al., 2006). This should not be seen as an invalidation of the QC/QA procedures followed in the past. On the contrary, they should be seen as the necessary steps having brought the data set to such a state that the discovery of the new features becomes possible.

The potential of the indicators related to atmospheric conditions has not yet been fully exploited in studies on the
Brewer \#037 UV irradiance data. Indeed, they could be used, for instance, to screen cases of extreme conditions, to be used in studies focusing on some particular atmospheric (radiative transfer) processes.

The cases flagged as GREY in the database may represent an interesting data set that could benefit model development and validation. The performance of 1-D radiative transfer models may be enhanced by replacing the plane-parallel layers of the atmosphere with a pseudo-spherical model of the atmosphere. This has been also realized in FastRT, improving its performance at high solar zenith angles and extending the usability of the model up to solar zenith angle (SZA) of at least $84^{\circ}$. The earliest versions of libRadtran (the basis of FastRT), in comparison, performed well up to $80^{\circ}$ (Mayer et al., 1997). Three-dimensional radiative transfer models like MYSTIC and McArtim (validated by Mayer et al. (2010) and Deutschmann et al. (2011), respectively) are more accurate and capable of simulating solar UV irradiance even up to $91^{\circ}$. Currently, these kinds of models remain too computationally intensive to be run on a server on an Oracle database. With the ever-advancing computer efficiencies, this may not be the case in the future.

\section{Conclusions}

The quality of solar spectral UV irradiance measured by Brewer \#037 spectroradiometer in 1990-2014 in Sodankylä, Finland, was examined using the quality assurance (QA) tools provided by the European UV DataBase (EUVDB). Data on the quality indicators, determined by the QA tool and attached to the spectra stored in the database, were retrieved and analysed. The data set appeared to extend over a quarter of a century with only minor gaps. The gaps in the time series could be traced to annual maintenance and total column ozone calibrations, intercomparison campaigns in Finland and abroad, regular lamp measurements in the laboratory for UV irradiance calibration, and occasional malfunctions due to, for example, problems with the software.

More importantly, the QA tools designed for and implemented in the database yielded important information on the quality of the measured spectra. Only $0.12 \%$ were flagged as BLACK, indicating severe flaws in the data. Over $90 \%$ of the four main quality indicators were flagged as GREEN, indicating the highest achievable quality.

For the master flag denoting the overall quality of the data, approximately $23 \%$ were flagged as GREY, denoting data that the QA tools were not able to make definitive conclusions on. A majority of the cases of this kind could be traced to the indicator related to atmospheric transmission and cases of high SZA. Due to the restrictions in the performance of the radiative transfer model FastRT used by the AtmosphericSignature tool, the algorithm marks cases of SZA greater than $84^{\circ}$ all as GREY. Therefore, for the Sodankylä Brewer \#037 UV irradiance spectra, the master flag, and the relative 
number of GREEN flags given to the master flag, may not be the most relevant indicator of the overall quality. For that purpose, the flags received by the individual quality indicators should be examined instead.

The results of this study support the view that the user of the database should familiarize himself/herself with the relevant documentation on the flagging system and the detailed flag information to be able to fully exploit the system. In addition, cooperation with the data provider, who has the best knowledge of the data, is highly recommendable to any user examining any data retrieved from the database.

The analysis on the performance of the QA tools and the conclusion drawn in this study are strictly valid only for the particular data set studied, i.e. solar spectral UV irradiance measured by Brewer \#037 in Sodankylä over the years 19902014. Further studies on the performance of the QA tools of the EUVDB should therefore cover a number of measurement sites and instruments. A follow-up study still focusing on the Sodankylä Brewer \#037 UV data in its unique setting at a high-latitude site is also planned. The study is intended to focus on the GREY flags for each quality indicator separately, to investigate the performance of the algorithm in these undetermined cases exclusively. Compatibility of cloudiness conditions determined by the QA tool and synoptic cloud observations would be another interesting topic for a further study.

\section{Data availability}

The data on the flag statistics used in this study are available at the European UV Database EUVDB for a registered user. Instructions on how to register may be found at the wwwpages of the database at http://uvdb.fmi.fi/uvdb/. Data are also provided as a supplement to this article.

\section{The Supplement related to this article is available online at doi:10.5194/gi-5-333-2016-supplement.}

Author contributions. A. Heikkilä contributed to the design of the European UV DataBase (EUVDB) and the implementation of the retrieval tools, conducted the statistical analysis for the Sodankylä case study, and prepared the manuscript. J. Kaurola contributed to the design of the www interface to the database and the tools implemented therein. K. Lakkala processed the spectral UV irradiance data from Brewer \#037 submitted to the EUVDB and performed the on-site QC/QA actions on the data. J. M. Karhu made the lamp measurements required for the QC and carried out the maintenance of the calibration of Brewer \#037. E. Kyrö initiated the measurements of spectral UV irradiance with Brewer \#037 in 1989 in Sodankylä. T. Koskela contributed to the overall QC/QA of the Brewer \#037. O. Engelsen developed the AtmosphericSignature QA tool implemented in the database. H. Slaper developed the ShicRIVM QA tool also implemented in the database. G. Seckmeyer coordinated the projects SUVDAMA and EDUCE, during which the database and its QA tools were designed and implemented.

Acknowledgements. The authors gratefully acknowledge the financial support from the European Union granted through the programmes FP4-ENV 2C and FP5-EESD for the projects SUVDAMA (Scientific UV DAta MAnagement) and EDUCE (European UV Database for Ultraviolet Radiation Climatology and Evaluation).

Edited by: N. Partamies

Reviewed by: two anonymous referees

\section{References}

Bais, A., Zerefos, C., and McElroy, C.: Solar UVB measurements with the double- and single-monochromator Brewer Ozone Spectrophotometers, Geophys. Res. Lett., 23, 833-836, 1996.

Bais, A. F., Gardiner, B., Slaper, H., Blumthaler, M., Bernhard, G., McKenzie, R., Webb, A.R., Seckmeyer, G., Kjeldstad, B., Koskela, T., Kirsch, P. J., Gröbner, J., Kerr, J. B., Kazadzis, S., Leszczynski, K., Wardle, D., Josefsson, W., Brogniez, C., Gillotay, D., Reinen, H., Weihs, P., Svenoe, T., Eriksen, P., Kuik, F., and Redondas, A.: SUSPEN intercomparison of ultraviolet spectroradiometers, J. Geophys. Res., 106, 12509-12525, 2001.

Bernhard, G., Seckmeyer, G., McKenzie, R., and Johnston, P.: Ratio spectra as a quality control tool for solar spectral UV measurements, J. Geophys. Res.-Atmos., 103, 28855-28861, 1998.

Brewer, A. W.: A replacement for the Dobson spectrophotometer?, Pure Appl. Geophys., 106-108, 919-927, 1973.

Cappellani, F. and Bielli, A.: Correlation between $\mathrm{SO}_{2}$ and $\mathrm{NO}_{2}$ measured in an atmospheric column by a Brewer spectrophotometer and at ground-level by photochemical techniques, Environ. Monit. Assess., 35, 77-84, 1995.

Cede, A., Herman, J., Richter, A., Krotkov, N., and Burrows, J.: Measurements of nitrogen dioxide total column amounts using a Brewer double spectrophotometer in direct Sun mode, J. Geophys. Res., 111, D05304, doi:10.1029/2005JD006585, 2006.

Deutschmann, T., Beirle, S., Frieß, U., Grzegorski, M., Kern, C., Kritten, L., Platt, U., Prados-Román, C., Puki, J., and Wagner, T.: The monte carlo atmospheric radiative transfer model McArtim: Introduction and validation of jacobians and 3D features, J. Quant. Spectrosc. Ra., 112, 1119-1137, 2011.

Diémoz, H., Siani, A. M., Redondas, A., Savastiouk, V., McElroy, C. T., Navarro-Comas, M., and Hase, F.: Improved retrieval of nitrogen dioxide $\left(\mathrm{NO}_{2}\right)$ column densities by means of MKIV Brewer spectrophotometers, Atmos. Meas. Tech., 7, 4009-4022, doi:10.5194/amt-7-4009-2014, 2014.

Garane, K., Bais, A. F., Kazadzis, S., Kazantzidis, A., and Meleti, C.: Monitoring of UV spectral irradiance at Thessaloniki (19902005): data re-evaluation and quality control, Ann. Geophys., 24, 3215-3228, doi:10.5194/angeo-24-3215-2006, 2006.

Gardiner, B. G. and Kirsch, P. J.: Intercomparison of ultraviolet spectroradiometers, Ispra, 24-25 May 1995, in: Advances in Solar Ultraviolet Spectroradiometry, Air Pollut. Res. Rep. 63, 67151, edited by: Webb, A. R., Eur. Commun., Luxembourg, 1997. 
Gröbner, J., Vergaz, R., Cachorro, V. E., Henriques, D. V., Lamb, K., Redondas, A., Vilaplana, J. M., and Rembges, D.: Intercomparison of aerosol optical depth measurements in the UVB using Brewer spectrophotometers and a Li-Cor spectrophotometer, Geophys. Res. Lett., 28, 1691-1694, 2001.

Karppinen, T., Lakkala, K., Karhu, J. M., Heikkinen, P., Kivi, R., and Kyrö, E.: Brewer spectrometer total ozone column measurements in Sodankylä, Geosci. Instrum. Method. Data Syst., 5, 229-239, doi:10.5194/gi-5-229-2016, 2016.

Kazadzis, S., Bais, A., Kouremeti, N., Gerasopoulos, E., Garane K., Blumthaler, M., Schallhart, B., and Cede, A.: Direct spectral measurements with a Brewer spectroradiometer: Absolute calibration and aerosol optical depth retrieval, Appl. Opt., 44, 16811690, 2005.

Koskela, T., Johnson, B., Bais, A. F., Josefsson, W., and Slaper, H.: Spectral sky measurements, in: The Nordic intercomparison of ultraviolet and total ozone instruments at Izana, October 1996, Izana, Meteorological Publications 36, edited by: Kjeldstad, B., Johnson, B., and Koskela, T.: Finnish Meteorological Institute, 89 pp., 1997.

Kurucz, R. L., Furenlid, I., Brault, J., and Testerman, L.: Solar flux atlas from 296 to $1300 \mathrm{~nm}$. National Solar Observatory Atlas, Sunspot, New Mexico, National Solar Observatory, Harvard University Press, Cambridge, MA, 1984.

Lakkala, K., Arola, A., Heikkilä, A., Kaurola, J., Koskela, T., Kyrö, E., Lindfors, A., Meinander, O., Tanskanen, A., and Gröbner, J.: Quality assurance of the Brewer spectral UV measurements in Finland, Atmos. Chem. Phys., 8, 3369-3383, doi:10.5194/acp-83369-2008, 2008.

Mäkelä, J. S., Lakkala, K., Meinander, O., Kaurola, J., Koskela, T., Karhu, J. M., Karppinen, T., Kyrö, E., de Leeuw, G., and Heikkilä, A.: In search of traceability: two decades of calibrated Brewer UV measurements in Sodankylä and Jokioinen, Geosci. Instrum. Method. Data Syst. Discuss., doi:10.5194/gi-2015-40, in review, 2016.

Marenco, F., di Sarra, A., and De Luisi, J.: Methodology for determining aerosol optical depth from Brewer 300-320-nm ozone measurements, Appl. Opt., 41, 1805-1814, 2002.

Mayer, B., Seckmeyer, G., and Kylling, A.: Systematic long-term comparison of spectral UV measurements and UVSPEC modeling results, J. Geophys. Res.-Atmos., 102, 8755-8767, 1997.

Mayer, B., Hoch, S. W., and Whiteman, C. D.: Validating the MYSTIC three-dimensional radiative transfer model with observations from the complex topography of Arizona's Meteor Crater, Atmos. Chem. Phys., 10, 8685-8696, doi:10.5194/acp-10-86852010, 2010.

McKenzie, R.: Application of a simple model to calculate latitudinal and hemispheric differences in ultraviolet radiation, Weather and Climate, 11, 3-14, 1991.

McKenzie, R. L., Bernhard, G., Madronich, S., and Zaratti, F.: Comment on "Record solar UV irradiance in the tropical Andes, by Cabrol et al."', Frontiers in Environmental Science, 3, 26 pp., 2015.

Seckmeyer, G.: Publications within SUVDAMA, available at: http://www1.muk.uni-hannover.de/ seckmeyer/EDUCE/results/ suvrefs.html (last modified: 15 July 2002, last access: 12 June 2016), 2002.

Seckmeyer, G.: Publications within EDUCE, available at: http://www1.muk.uni-hannover.de/ seckmeyer/EDUCE/results/ publications.html (last modified: 26 February 2004, last access: 12 June 2016), 2004.

Seckmeyer, G., Bais, A., Bernhard, G., Blumthaler, M., Booth, C. R., Disterhoft, P., Eriksen, P., McKenzie, R. L., Miyauchi, M., and Roy, C.: "Instruments to Measure Solar Ultraviolet Radiation: Part 1: Spectral Instruments", Global Atmosphere Watch (GAW) Report No. 125, WMO TD No. 1066, World Meteorological Organization (WMO), Geneva, 2001.

Seckmeyer, G., Bais, A., Bernhard, G., Blumthaler, M., Booth, C., Lantz, K., McKenzie, R., Disterhoft, P., and Webb, A.: Instruments to measure solar ultraviolet radiation. Part 2: Broadband instruments measuring erythemally weighted solar irradiance, Global Atmosphere Watch (GAW) Report No. 164, WMO TD No. 1289, World Meteorological Organization (WMO), Geneva, 2005.

Seckmeyer, G., Glandorf, M., Wichers, C., McKenzie, R., Henriques, D., Carvalho, F., Webb, A., Siani, A.-M., Bais, A., Kjeldstad, B., Brogniez, C., Werle, P., Koskela, T., Lakkala, K., Gröbner, J., Slaper, H., den Outer, P., and Feister, U.: Europe's darker atmosphere in the UV-B, Photoch. Photobio. Sci., 7, 925-930, 2008a.

Seckmeyer, G., Pissulla, D., Glandorf, M., Henriques, D., Johnsen, B., Webb, A., Siani, A.-M., Bais, A., Kjeldstad, B., Brogniez, C., Lenoble, J., Gardiner, B., Kirsch, P., Koskela, T., Kaurola, J., Uhlmann, B., Slaper, H., den Outer, P., Janouch, M., Werle, P., Gröbner, J., Mayer, B., de la Casiniere, A., Simic, S., and Carvalho, F.: Variability of UV irradiance in Europe, Photochem. Photobiol., 84, 172-179, 2008b.

Seckmeyer, G., Bais, A., Bernhard, G., Blumthaler, M., Drüke, S., Kiedron, P., Lantz, K., McKenzie, R. L., and Riechelmann, S.: Instruments to Measure Solar Ultraviolet Radiation Part 4: Array Spectroradiometers, Global Atmosphere Watch (GAW) Report No. 191, TD No. 1538, World Meteorological Organization (WMO), Geneva, 2010a.

Seckmeyer, G., Bais, A., Bernhard, G., Blumthaler, M., Johnsen, B., Lantz, K., and McKenzie, R.: Instruments to Measure Solar Ultraviolet Radiation Part 3: Multi-channel filter instruments, Global Atmosphere Watch (GAW) Report No. 190, TD No. 1537, World Meteorological Organization (WMO), Geneva, $2010 b$.

Shettle, E. P.: Models of aerosols, clouds, and precipitation for atmospheric propagation studies, in: AGARD, Atmospheric Propagation in the UV, Visible, IR, and MM-Wave Region and Related Systems Aspects 14 p. (SEE N90-21907 15-32), 1990.

Slaper, H. and Koskela, T.: Methodology of intercomparing spectral sky measurements, correcting for wavelength shifts, slit function differences and defining a spectral referencce, in: The Nordic intercomparison of ultraviolet and total ozone instruments at Izana, October 1996, Izana, Meteorological Publications 36, edited by: Kjeldstad, B., Johnson, B., and Koskela, T., Finnish Meteorological Institute, 89 pp., 1997.

Slaper, H., Reinen, H., Blumthaler, M., Huber, M., and Kuik, F.: Comparing ground-level spectrally resolved solar UV measurements using various instruments: A technique resolving effects of wavelength shift and slit width, Geophys. Res. Lett., 22, 27212724, 1995.

Voskrebenzev, A., Riechelmann, S., Bais, A., Slaper, H., and Seckmeyer, G.: Estimating probability distributions of solar irradiance, Theor. Appl. Climatol., 119, 465-479, 2015. 
Webb, A. R., Gardiner, B. G., Martin, T. J., Leszczynski, K., Metzdorf, J., and Mohnen, V. A.: Guidelines for site quality control of UV monitoring, Global Atmosphere Watch (GAW) Report No. 126, TD No. 884 edn., World Meteorological Organization (WMO), Geneva, 1998.

Webb, A. R., Gardiner, B. G., Leszczynski, K., Mohnen, V., Johnston, P., Harrison, N., and Bigelow, D.: Quality Assurance in Monitoring Solar Ultraviolet Radiation: the State of the Art, World Meteorological Organization, Global Atmosphere Watch Publication, GAW Report No. 191, WMO TD No. 1180, 2003.
Williams, J., den Outer, P., and Slaper, H.: Quality assurance of solar spectral UV-measurements: methods and use of the SHICrivm software tool, EGS-AGU-EUG Joint Assembly, 13394 pp., 2003. 